\title{
Reader Education in Libraries of Universities
}

\author{
Chunlan Qiu \\ Jiangxi University of Science and Technology \\ Ganzhou, Jiangxi 341000, China \\ E-mail: jxust@126.com \\ Yan Liu \\ Zhejiang Business Technology Institute \\ Ningbo, Zhejiang 315012, China \\ E-mail: jxust@163.com
}

\begin{abstract}
This paper, starting from the signification, the importance and the meaning of reader education, discusses how libraries of schools of higher education can, under the new situation, carry out researches on readers in depth, understand the demands of readers, do a good job in reader education in libraries, and help students to fully make use of various literature materials of libraries.
\end{abstract}

Keywords: Libraries of schools of higher education, Reader work, Reader education

Library of school of higher education, as the information resource and the technology compositive place and with their rich literature information resources stored in libraries and elegance and comfortable learning environment, becomes an indispensable learning place for students. Teachers and students have increasingly acknowledged the importance of information gaining, information reading and assessing and capacity education.

As is well known, the level of library readers, especially the level of capacity in searching and making use of literature information resources of libraries, influences the using rate of the literature information stored in the libraries to great extent. That is to say, if readers are all good at making use of literature information of libraries, the circulation degree of literature resources stored in libraries will be higher and more sufficient. With the enlargement of the teaching scale of schools of higher education and the increase of the popularization degree of university education, the function of the library education of schools of higher education becomes increasingly important. Library, as one of the three backbones in schools of higher education, shall of course be the "second class". Libraries will exert better functions by way of carrying out reader education.

\section{The signification of reader education}

Mews, British library scholar, defined reader education in her book, Reader Education, as "a kind of education that helps readers to use libraries the best". Li Xikong pointed out in Generality of Library Reader Study that "reader education is an education that libraries and other information organs carry out to cultivate and raise the capacities of readers to make use of literature information." To put it in detail, reader education refers to by activities, such as planning with pertinence, propaganda promotion of various modes, and special trainings, and by introducing the gaining methods or search strategies of information resources of various types and carriers, and by library service, to cultivate and improve information consciousness and library using capacity of readers. In addition, to actively cultivate readers' feelings towards libraries is also a task of reader education. Anyway, reader education is one of the important items in reader work of libraries.

\section{The importance of reader education}

The educational function of libraries becomes increasingly important in higher education. One of the social functions of libraries is educational function; therefore, whether from objective or subjective aspect, library education is responsible for raising the information makings of readers. Once the information makings of readers are improved, readers will be able to make use of libraries better, which will advance libraries to take initiative to explore and develop more actively and comprehensively.

In the process of using libraries, readers will consciously or unconsciously place their hopes on libraries, hoping that libraries can help them to raise information makings. Through common efforts of libraries and readers, the information 
makings of readers will be improved; therefore, the capacity of readers to obtain and use information and the innovation capacity of readers will also be improved, which shows that the development of libraries and the improvement of the information makings of readers supplement each other.

\section{The meanings of reader education}

3.1 To help to enhance the library consciousness of readers and increase the using rate of information stored in the libraries.

The meanings of reader education lie in that it carries out library knowledge education to readers, popularizes literature search methods, helps readers fully understand libraries, stimulates the potential reading demands of readers and the enthusiasm of readers in using libraries, which can put the information stored being left unused into use and can decrease the waste of literature resources.

\subsection{To help to improve the information makings and self-study capacity of readers and help readers to build up successful personality}

In information society, with the quickening of the speed of the change of knowledge and information, the capacity of readers to personally make use of and process information becomes an important element in determining the development of readers. Personal development capacity of readers will to great extent depend on the capacity of readers in continuously making use of new information to carry out self-study and self-education rather than the original knowledge level of the readers. Obviously, a person who is emerged in an information ocean but knows nothing to do will not succeed in this information error. Descartes, a famous scientist once said, "The most useful knowledge is knowledge about methods". The authors of this paper have been engaged in book lending work for years. In the work, the authors found that many readers did not have express book borrowing aim, were not clear about reading selection standard and did not know how to find literatures they actually needed. Libraries can carry out guidance education to them so as to improve their capacity in reaching, recognizing, evaluating and selecting various literature information, by which way readers can be able to select the books that are most suitable, to form good reading habits, to improve self-study capacity, to cultivate culture, and to build up successful personality.

\subsection{To provide readers with the key to the knowledge treasures so as to save the precious time of readers.}

Now the world is at information explosion era and the literature information is immense. To teach readers to use various search tools and to master ways and techniques of searching literature can equip readers with the awareness of information and information capacity. Besides, readers are familiar with their own specialties, which will help readers to recognize the use value of information resources. The key for readers to open knowledge treasures will save a lot of time for readers when searching reference materials and can utmost realize the use values of information.

\subsection{To enable information to exert social and economical benefit.}

The purpose of obtaining information is to generate new information growth points and realize the use value of information. Libraries teach readers the ways and steps to use various literature information so as to help readers to make use of the effective information collected and selected and theoretical knowledge to solve problems in work, study, life and science and technology, which can realize the ultimate aim of knowledge information in serving the society and economy.

\section{The exertion of the educational functions of libraries}

In the $21^{\text {st }}$ century, new educational concept emphasizes more on making education of people. The cultivation of college students gradually changes from single type education to integrative type education. The reading inclination of college readers has undergone obvious changes and development. In the past, after school reading contents of college readers were basically limited to public courses, specialty fundamental courses and specialty courses. Due to the reform of teaching and education, schools of higher education continuously renew teaching contents, compress or abrogate old and repetitive specialty contents, adjust course set-up, re-organize course system, mutually penetrate human science and natural science, reduce compulsory courses, and increase selective courses so as to enlarge students' vision and cultivate integrative making of students. Hence, college readers not only need to read books on their specialty and teaching reference literatures, but also need to reader cross discipline and cross specialty literatures. Students of human science borrow books on mathematics, physics, chemistry, industrial technology (mainly computer science); students of natural science borrow books on languages, literature, economics, and philosophy, religion, politics and history, which is a new trend in diligent college students. College students undergo several study stage from the time they enter school to their graduation, therefore, we need to provide them with pertinent literature information materials according to their study tasks and aims in different study stages so as to exert the educational functions of libraries.

\subsection{Freshman stage}

When freshmen first enter their universities, they feel confused about how to choose books from various books in libraries. They lack knowledge about the feature, status and functions of university libraries and know little about 
catalog searching, contents stored in the library and service set-up of libraries, which results in that freshmen do not know how to make use of libraries in a rather long time since their entrance to universities. Besides, freshmen are shy when first contacting librarians and are not willing to inquire librarians about the use methods of libraries. Therefore, blind and random borrowing and reading appear in freshmen. They read whatever they get to borrow or they read what others read, which not only wastes their own time but also causes unnecessary troubles for library workers. With regards to those problems, libraries shall take initiative to carry out entrance education to readers about "how to make use of libraries", where libraries can take the chance to introduce to freshmen the nature, tasks and development history of libraries, the set-up and functions of service organs in libraries, and the technical methods, such as classification system and research methods. In addition, libraries shall introduce to readers the problems that should be noted when using reading rooms, shall introduce the use methods of tool books by ways of personal answering and word explanation, shall provide students with teaching reference books according to the teaching, and can introduce to readers or directly provide readers with the literature materials by way of catalog, brief introduction and book comments. Libraries can through active and vivid reading activities carry out various reading leading work to cultivate the study interests of freshmen and help freshmen to set up correct life view. After school, libraries can organize students to pay visit to libraries and introduce library to them according to their class contents. By this direct impression, readers can get to know the substantiality of library and the research methods for literature information, which can help to reduce the blindness in reading and borrowing, increase the correctness, and cultivate the most basic information obtaining capacity and information accepting awareness. By this way, readers will learn how to find books for themselves and how to independently and reasonably make use of library; will continuously enlarge and enrich their knowledge. Hence, the self-study capacity and thinking capacity of students are built up.

In addition, personnel of library circulation service department can inform students of the problems that the personnel are unusually confronted with in daily work and that students need to pay attention to so as to arouse the attention of students; therefore, students can assist and help advance the smooth development of the work of library.

Library shall also need to open Literature Search and Use course for college students of human science and natural science, which will teach students methods on searching literature and guide students in searching literatures. Libraries of schools of higher education and public libraries all need to open literature search course in scheduled period to pertinently introduce how to search knowledge, aiming at help readers to master relevant search tools, improve the capacity of knowledge search, analysis, integration and evaluation of reader, and lay a solid foundation for knowledge renewal and technology innovation. Libraries can also edit the teaching plan for literature search course that suitable for their own schools and incorporate the plan into the teaching plan of their schools, which will greatly improve the learning making of college students.

\subsection{Specialty course study stage}

After students enter into the specialty course study stage, students will from various study attitudes because of different acknowledgement of their specialty courses; therefore, libraries shall take various ways to carry out reading guidance. For example, some students have great interests toward their specialty, while facing the enormous book ocean, they are eager to find a shortcut. For this kind of situation, library can adopt the combination of common reading guidance and key reading guidance, which means that library can commonly recommend specialty reference books and edit relevant recommendation catalog and at the same time, focus on the difficulties that students are encountered with in study and help students to resolve the difficulties with germane book information materials. For another example, some students may have strong interests in knowledge beyond their specialties and want to spend more time on learning the knowledge they are interested in. The reading scale of this kind of students is extensive. Knowledge on ancient history, foreign cultures, chronometer and geography are all what they want to get to absorb. With regards to this kind of situation, libraries should direct them to master their specialty courses and meanwhile, direct them to learn other knowledge selectively and with emphasis so as to avoid sciolistic phenomenon. Some students are of the view that after entering colleges, they can relax. Therefore, they are just in pursuit of entertainment and choose to reader romance and martial art books. Some even read unhealthy, colorful and reactionism books. To deal with these problems, libraries shall be good at making use of the literature resources stored and combine social hot issues, focus issues, and the situation home and abroad to hold various exhibition activities to carry out political and idealism education on students. Through fact educations, libraries can help students to improve their mortal actions, value concepts and specialty knowledge, to cultivate their noble sentiment and courtlike reading interests, and improve their acknowledgement of specialty study.

\subsection{Graduation practice stage}

The main task of students in this stage is to finish graduation practice and graduation design (graduation thesis paper). Students at this stage have mastered fundamental discipline knowledge and certain specialty knowledge. This stage is a preparation stage for them to enter into society and a formation stage of their integrative capacity and innovation capacity. After entering this stage, the study consciousness of students is rather strong. Class study cannot meet their 
demands. Besides, they are near graduation. Some students need to prepare materials for their graduation design and thesis paper writing. Some students need to search materials for their further education after graduation. Therefore, libraries shall take active and effective measures to help students to finish this key study stage. The reference books needed in graduation practices and thesis paper writing are comparatively centralized. Libraries shall prepare in advance the books students need and shall recommend to students the relevant reference books of the same type but of different names when the supply and demand contradicts appear. Periodical reading rooms can make use of the short publishing period and huge information amount of periodicals as wall as the centralized discipline knowledge to edit article indexes for graduates. Libraries, who are able to, can take advantage of network to provide graduates with internet information resources to cultivate graduates' capacity in using computers to search electric literatures and to gain internet information. By this way, graduates' capacity in information gaining and analysis are improved, which can help graduates to enter into society and serve the society.

In addition, with regard to various problems and difficulties that readers meet in using libraries and various information search tools, libraries can provide timely personal consultation education, such as to set up consultation posts inside libraries to carry out face to face consultation or telephone consultation. In a word, reader making education can be carried out in various and flexible ways.

\section{Conclusion}

No matter it is in the past or in the future, reader education has always been an eternal subject in reader work of libraries, the basic function of library work, the basic demand of reader work, and the important constitute of reader service work. With the continuous development of library career, the function of reader education becomes more and more important. The reader education of libraries advances the exploration and the use of literature resources, cultivates the capacities of readers, and pushes the continuous development and improvement of libraries in meeting the demands of readers, which in turn pushes the development of the entire library career.

\section{References}

Long Xuntian.(2002).New concept of reader work. Library Forum, (3):74-75

Wu, Weici \& Shao, Ji.(1986).General Study of Library Science. Beijing: Book Catalog Literature Press. 